\title{
Supply chain coordination via a two-part tariff contract with price and sales effort dependent demand
}

\author{
Qinqin Li* and Zhiying Liu
}

School of Management, University of Science and Technology of China, Hefei 230026, China

\begin{tabular}{l}
\hline C H R O N I C L E \\
\hline Article history: \\
Received March 15, 2014 \\
Accepted September 6, 2014 \\
Available online \\
September 92014 \\
\hline Keywords: \\
Channel coordination \\
Sales effort \\
Two-part tariff \\
Contract \\
Game theory
\end{tabular}

A B S T R A C T

\begin{abstract}
This paper studies the channel coordination between a supplier and a retailer with price and sales effort dependent demand. By means of game theory, we analyze price and sales effort decisions of the centralized supply chain. Then we consider three different contracts under decentralized model, i.e., wholesale price contract, cost-sharing contract and a two-part tariff contract, in which the supplier offers a contract comprising a wholesale price and a lump-sum fee to the retailer to coordinate the supply chain. Finally, we analyze the results to compare the equilibrium decisions under different contract scenarios. Our results show that both the wholesale price contract and the cost-sharing contract cannot coordinate the supply chain while the two-part tariff contract can effectively coordinate the supply chain.
\end{abstract}

(C) 2015 Growing Science Ltd. All rights reserved.

\section{Introduction}

Faced with more intensified market competition than ever before, the retailers must focus on more complicated strategies than simply lowering the price. They have to emphasize the importance of non-price factors, such as service, quality or sales effort, which have become more important in affecting consumers' purchase decisions (Lu et al., 2011; Tsay \& Agrawal, 2000; Boyaci \& Gallego, 2004). The retailers may provide various sales efforts, such as pre-sale and after-sale service, product advertising, responsive product repair, in order to increase the attractiveness of the products. A parallel stream of literature, represented by McGuire and Staelin (1983), focused on the channel coordination problem. Prior studies have discussed a variety of contracts under various environments, such as wholesale price (Bernstein et al., 2006), buy-back (Wu, 2011; Hou et al., 2010), revenue sharing (Cachon \& Lariviere, 2005; Giannoccaro \& Pontrandolfo, 2004; Yao et al., 2008; Linh \& Hong, 2009), quantity flexibility (Sethi et al., 2004; Tsay, 1999), sales-rebate (Wong et al., 2009; Taylor, 2002). However, the above literature didn't address issues about channel coordination with price and sales effort dependent demand. 
Sales effort or service problems have been viewed as an important strategy and have received wide attention in the marketing literature and operations literature. Prior studies have examined price and service decisions under channel competition (Tsay \& Agrawal, 2000; Chen et al., 2008; Bernstein \& Federgruen, 2004; Dan et al., 2012), optimal coordination design and coordination (Bernstein \& Federgruen, 2007; Mukhopadhyay et al., 2009; Ma et al., 2013a; Krishnan et al., 2004; He et al., 2009) and effects of the channel power structures (Lu et al., 2011; Tang et al., 2012; Gurnani et al., 2007; Karray, 2013). Perry and Porter (1990) investigated resale price maintenance by a monopoly manufacturer who sells its product through monopolistically competitive retailers when the retailers provide service. Tsay and Agrawal (2000) studied a distribution system consisting of a manufacturer and two independent retailers under price and service competition. Lu et al. (2011) outlined a gametheoretic framework to obtain the equilibrium solutions for two competing manufacturers and their common retailer when the demand is sensitive to both retail price and manufacturer service. They compared results from three supply chain structures: manufacturer Stackelberg, retailer Stackelberg and vertical Nash. Ma et al. (2013a) developed models to optimize the retailer's and the manufacturer's effort levels and profits using different channel strategies. Similarly, Gurnani et al. (2007) and Karray (2013) examined the effect of the periodicity of pricing and marketing efforts on the equilibrium outcomes.

Some research has begun to emerge in the area of the coordination of supply chain when the demand is sensitive to both price and non-price factors. Iyer (1998) analyzed the channel coordination issues of manufacturers when retailers compete in price as well as non-price factors such as the provision of product information, free repair, faster check-out, or after-sales service. Krishnan et al. (2004) investigated coordination contracts for decentralized supply chains with retailer promotional effort and analyzed supply chain coordination by coupling buy-backs with promotional cost-sharing agreements, offering unilateral markdown allowances ex post, or placing additional constraints on the buy-back. Bernstein and Federgruen (2007) compared the coordination mechanisms when retailers compete only in terms of their prices, and when they engage in simultaneous price and service competition. Mukhopadhyay et al. (2009) studied a distribution channel in which a manufacturer relies on a sales agent for selling the product and for investing in marketing effort. They proposed two contract forms: a two-part price schedule specifying a variable wholesale price and a fixed franchise fee. He et al. (2009) and Ma et al. (2013b) also investigated the issue of channel coordination with effort and price dependent demand.

Our work deals with supply chain coordination when the demand is sensitive to both price and sales effort. Unlike previous studies, we model different decision making structures (the centralized supply chain and decentralized supply chain) in a supply chain where the retailer undertakes sales effort to increase the market demand. In centralized supply chain, the members are managed by a dominant decision maker aiming to maximize the total expected profit of the supply chain, while decentralized supply chain, each member's objective is to maximize his own profit. We investigate wholesale price contract and cost-sharing contract in the decentralized supply chain model and develop a two-part tariff contract to coordinate the supply chain, in which the supplier offers a contract comprising a wholesale price and a lump-sum fee to the retailer.

The remainder of this paper is organized as follows. Section 2 gives model description. Section 3 analyzes the centralized supply chain model. Section 4 examines the decentralized scenario under three models of different contracts, i.e., wholesale price contract model, cost-sharing contract model and a two-part tariff contract model to coordinate the supply chain. Section 5 analyzes the results to compare the equilibrium decisions under different contract scenarios. Section 6 concludes the paper.

\section{Model Description}

We consider a two-echelon supply chain consisting of one supplier and one retailer. The demand is 
assumed to be deterministic and all model parameters are common knowledge for both players. To maintain analytical tractability, we don't consider the retailer's marginal cost. We discuss price and service decisions of players in different models: centralized supply chain, wholesale price contract model and cost-sharing contract model. Similar to the prior literature (Tsay \& Agrawal, 2000), we assume that the demand function is

$D=a-b p+\beta x$

Here we assume the demand is more sensitive to price $p$ than to service $x$, that is, $b>\beta$. Furthermore, we assume that, when the retailer provides a sales effort $x$, the effort cost is $\frac{1}{2} r x^{2}$, which assures that the profit function is concave on $x$, i.e., improving service has a decreasing return on sales effort expenditure (Tsay \& Agrawal, 2000). In our model, the supplier is assumed to be the leader in the Stackelberg game setting. The supplier determines the wholesale price and the retailer decides the retailer price and sales effort.

\section{The centralized supply chain model}

In the centralized supply chain model, the supply chain members seek to maximize the whole supply chains' profit.

The profit for the centralized supply chain can be expressed as:

$\pi_{s c}=(p-c)(a-b p+\beta x)-\frac{1}{2} r x^{2}$

Hessian matrix of $\pi_{s c}$ is

$$
H_{1}=\left[\begin{array}{cc}
-2 b & \beta \\
\beta & -r
\end{array}\right]
$$

The utility function $\pi_{s c}$ is a concave function on $(p, x)$ if and only if Hessian matrix is negative definite. Let $B_{1}=2 b r-\beta^{2}$.

Solving the first order condition of Eq.(2), we find the following.

Proposition 1. In the centralized supply chain model, if $B_{1}>0$, then the optimal retail price and sales effort are

$$
\begin{aligned}
p^{c^{*}} & =\frac{r b c-\beta^{2} c+r a}{2 b r-\beta^{2}}, \\
x^{c^{*}} & =\frac{\beta(a-b c)}{2 b r-\beta^{2}} .
\end{aligned}
$$

After substituting Eq. (3) and Eq. (4) into Eq. (1) and Eq. (2), we derive the demand and the profit of the supplier chain as follows,

$$
D^{c^{*}}=\frac{r b(a-b c)}{2 b r-\beta^{2}}, \quad \pi_{s c}^{c^{*}}=\frac{r(a-b c)^{2}}{2\left(2 b r-\beta^{2}\right)} .
$$

\section{The decentralized supply chain model}

\subsection{Wholesale price contract model}

In the case of wholesale price contract model, the supplier determines the wholesale price first. The retailer observes the wholesale price and makes his/her response to set his/her optimal retail price and sales effort as the follower. The profit of the supplier and the retailer can be expressed as follows, 
$\pi_{s}=(w-c)(a-b p+\beta x)$,

$\pi_{r}=(p-w)(a-b p+\beta x)-\frac{1}{2} r x^{2}$.

Given the wholesale price, the retailer determines $p$ and $x$ to maximize his/her profit, shown as Eq. (6). Solving the first order condition for Eq. (6) yields the optimal retail price and sales effort is as follows,

$$
\begin{aligned}
& p^{w p}=\frac{-w \beta^{2}+w b r+r a}{2 b r-\beta^{2}}, \\
& x^{w p}=\frac{\beta(a-b w)}{2 b r-\beta^{2}} .
\end{aligned}
$$

Substituting Eq. (7) and Eq. (8) into Eq.(5), the supplier's optimal problem becomes

$$
\max \pi_{s}=(w-c)\left[a-b \cdot \frac{-w \beta^{2}+w b r+r a}{2 b r-\beta^{2}}+\beta \cdot \frac{\beta(a-b w)}{2 b r-\beta^{2}}\right]
$$

Solving the first order condition of Eq. (9), we derive the optimal wholesale price as follows,

$w^{w p^{*}}=\frac{a+c b}{2 b}$.

Proposition 2. In the wholesale price contract model, the optimal wholesale price is

$$
w^{w p^{*}}=\frac{a+c b}{2 b},
$$

and the optimal retail price and sales effort are as follows,

$$
\begin{aligned}
p^{w p^{*}} & =\frac{-\beta^{2}(a+b c)+r b(3 a+b c)}{2 b\left(-\beta^{2}+2 b r\right)} \\
x^{w p^{*}} & =\frac{\beta(a-b c)}{2\left(-\beta^{2}+2 b r\right)}
\end{aligned}
$$

Using Eq. (12) and Eq. (13), we derive the demand, the profit of the supplier, the retailer and the supply chain.

$$
D^{w p^{*}}=\frac{r b(a-b c)}{2\left(-\beta^{2}+2 b r\right)}, \pi_{s}^{w p^{*}}=\frac{r(a-b c)^{2}}{4\left(-\beta^{2}+2 b r\right)}, \pi_{r}^{w p^{*}}=\frac{r(a-b c)^{2}}{8\left(-\beta^{2}+2 b r\right)}, \pi_{s c}^{w p^{*}}=\pi_{s}^{w p^{*}}+\pi_{r}^{w p^{*}}=\frac{3 r(a-b c)^{2}}{8\left(-\beta^{2}+2 b r\right)} .
$$

\subsection{Cost-sharing contract model}

In the cost-sharing contract model, the supplier shares the retailer's sales effort cost. $0<\mathrm{k}<1$ is the fraction of the effort cost that the supplier pays, while the retailer undertakes the remaining $1-\mathrm{k}$ portion of the cost in sales effort. Thus, the supplier determines the wholesale price and the proportion of cost sharing first. The retailer observes the decisions of the supplier and makes his/her response to set his/her optimal retail price and sales effort as the follower. The profit of the supplier and the retailer can be expressed as follows,

$$
\begin{aligned}
& \pi_{s}=(w-c)(a-b p+\beta x)-k \cdot \frac{1}{2} r x^{2}, \\
& \pi_{r}=(p-w)(a-b p+\beta x)-(1-k) \cdot \frac{1}{2} r x^{2} .
\end{aligned}
$$

Given the wholesale price and the proportion of cost sharing, the retailer determines $p$ and $x$ to maximize his/her profit, shown as Eq. (15). Solving the first order condition of Eq. (15), we find that the optimal retail price and sales effort is as follows,

$$
p_{c s}=\frac{r(b w+a)(1-k)-\beta^{2} w}{2 r b(1-k)-\beta^{2}},
$$


$x_{c s}=\frac{\beta(a-b w)}{2 r b(1-k)-\beta^{2}}$.

Substituting Eq. (16) and Eq. (17) into Eq.(14), the supplier's profit becomes

$\pi_{s}=(w-c)\left(a-b \cdot \frac{r(b w+a)(1-k)-\beta^{2} w}{2 r b(1-k)-\beta^{2}}+\beta \cdot \frac{\beta(a-b w)}{2 r b(1-k)-\beta^{2}}\right)-k \cdot \frac{1}{2} r\left[\frac{\beta(a-b w)}{2 r b(1-k)-\beta^{2}}\right]^{2}$

Solving the first order condition of Eq. (18), we derive the optimal wholesale price and the optimal proportion of cost sharing as follows,

$w^{c s^{*}}=\frac{8 b r(a+b c)-3 \beta^{2}(a+2 b c)}{b\left(-9 \beta^{2}+16 r b\right)}$

$k^{c s^{*}}=\frac{1}{3}$

After substituting Eq. (19) and Eq. (20) into Eq. (16) and Eq. (17), we derive the following.

Proposition 3. In the cost-sharing contract model, then the optimal wholesale price and proportion of cost sharing is follows,

$w^{c s^{*}}=\frac{8 b r(a+b c)-3 \beta^{2}(a+2 b c)}{b\left(-9 \beta^{2}+16 r b\right)}$,

$k^{c s^{*}}=\frac{1}{3}$,

and the optimal retail price and sales effort are as follows,

$$
\begin{aligned}
& p^{c s^{*}}=\frac{12 r a b+4 r b^{2} c-3 a \beta^{2}-6 \beta^{2} b c}{b\left(-9 \beta^{2}+16 r b\right)}, \\
& x^{c s^{*}}=\frac{6 \beta(a-b c)}{-9 \beta^{2}+16 b r} .
\end{aligned}
$$

From Eq. (23) and Eq. (24), we derive the demand, the profit of the supplier, the retailer and the supply chain.

$$
\begin{aligned}
& D^{c s^{*}}=\frac{4 r b(a-b c)}{-9 \beta^{2}+16 r b} \\
& \pi_{s}^{c s^{*}}=\frac{2 r(a-b c)^{2}}{-9 \beta^{2}+16 r b}, \pi_{r}^{c s^{*}}=\frac{4 r(a-b c)^{2}\left(4 r b-3 \beta^{2}\right)}{\left(-9 \beta^{2}+16 r b\right)^{2}}, \pi_{s c}^{c s^{*}}=\pi_{s}^{c s^{*}}+\pi_{r}^{c s^{*}}=\frac{6 r(a-b c)^{2}\left(-5 \beta^{2}+8 r b\right)}{\left(-9 \beta^{2}+16 r b\right)^{2}}
\end{aligned}
$$

\subsection{Two-part tariff contract model}

We propose a simple two-part tariff contract, $(\mathrm{F}, \mathrm{w})$, to coordinate the supply chain in which the supplier charges the retailer a wholesale price along with a lump-sum fee. Such a contract can prompt the supplier to lower the wholesale price in exchange for a fixed payment (Ma et al., 2013a). In addition, the wholesale price is higher than the unit marginal cost of the supplier. With the two-part tariff contract, the profits of the supplier and the retailer are as follows,

$$
\begin{aligned}
& \pi_{s}=(w-c)(a-b p+\beta x)+F \\
& \pi_{r}=(p-w)(a-b p+\beta x)-\frac{1}{2} r x^{2}-F
\end{aligned}
$$

Differentiating $\pi_{r}$ with respect to $p$ and equating it to 0 yields,

$p=\frac{a+\beta x+w b}{2 b}$.

Substituting the values of $x^{c^{*}}$ into the above equation, we get 
$p^{t p t}=\frac{a+\frac{\beta^{2}(a-b c)}{-\beta^{2}+2 \eta b}+w b}{2 b}$

Equating $p^{\text {tpt }}$ to $p^{c^{*}}$, we get

$w=c$.

Substituting $p^{c^{*}}, x^{c^{*}}$ and Eq. (29) into Eq.(25) yields,

$\pi_{s}=\frac{\left(-r \beta^{2}+2 \eta^{2} b\right)(a-b c)^{2}}{2\left(-\beta^{2}+2 \eta b\right)^{2}}-F$

Since the retailer has to make positive profit, we get

$F<\frac{\left(-r \beta^{2}+2 \eta^{2} b\right)(a-b c)^{2}}{2\left(-\beta^{2}+2 \eta b\right)^{2}}$

Proposition 4. The two-part tariff contract between the supplier and retailer given by $w=c$ and $0<F<\frac{\left(-r \beta^{2}+2 \eta^{2} b\right)(a-b c)^{2}}{2\left(-\beta^{2}+2 \eta b\right)^{2}}$ coordinates the supply chain in the decentralized supply chain strategy.

Proposition 4 suggests that the supplier would charge a wholesale price that is just sufficient to recover its unit marginal cost. Thus, the retailer has incentives to lower the retail price. However, the supplier would boost its profits through the fixed fee. The upper bound on the fixed fee (F) ensures that the retailer would participate in the contract. In addition, the lower bound on fixed fee (F) keeps the fixed fee contract non-negative. The two-part tariff contract is the outcome of a bargaining process for the supply chain members. When the supplier and the retailer agree to share the total profit of the supply chain, they negotiate the value of the contract parameter $\mathrm{F}$ that is transferred from the retailer to the supplier. The fixed fee $\mathrm{F}$ will depend on the relative channel bargaining power that each member carries.

\section{Analysis}

In this section, we compare the optimal retail price, sales effort, demand and the supply chain profit of the three models: centralized supply chain, wholesale price contract model and cost-sharing contract model. For the ease of analysis, we summarize in Table 1.

\section{Table 1}

Summary of the equilibrium decisions under different contract scenarios

\begin{tabular}{|c|c|c|c|}
\hline $\begin{array}{l}\text { The optimal } \\
\text { values }\end{array}$ & $\begin{array}{l}\text { centralized supply } \\
\text { chain }\end{array}$ & wholesale price contract & cost-sharing contract \\
\hline retail price & $\frac{r b c-\beta^{2} c+r a}{\beta^{2}}$ & $-\beta^{2}(a+b c)+r b(3 a+b c)$ & $12 r a b+4 r b^{2} c-3 a \beta^{2}-6 \beta^{2} b c$ \\
\hline \multirow[b]{2}{*}{ sales effort } & $\beta(a-b c)$ & $\beta(a-b c)$ & $\begin{array}{c}b(-9 p+10 r D) \\
6 \beta(a-b c)\end{array}$ \\
\hline & $\frac{\beta(a-)^{2}}{2 b r-\beta^{2}}$ & $\frac{\rho(u-2 r)}{2\left(-\beta^{2}+2 b r\right)}$ & $\frac{0 \beta(u-v c)}{-9 \beta^{2}+16 b r}$ \\
\hline \multirow{2}{*}{ demand } & $r b(a-b c)$ & $r b(a-b c)$ & $4 r b(a-b c)$ \\
\hline & $\overline{2 b r-\beta^{2}}$ & $\overline{2\left(-\beta^{2}+2 b r\right)}$ & $\overline{-9 \beta^{2}+16 r b}$ \\
\hline \multirow{2}{*}{$\begin{array}{c}\text { the supply chain } \\
\text { profit }\end{array}$} & $r(a-b c)^{2}$ & $3 r(a-b c)^{2}$ & $6 r(a-b c)^{2}\left(-5 \beta^{2}+8 r b\right)$ \\
\hline & $\overline{2\left(2 b r-\beta^{2}\right)}$ & $\overline{8\left(-\beta^{2}+2 b r\right)}$ & $\left(-9 \beta^{2}+16 r b\right)^{2}$ \\
\hline
\end{tabular}

(1) Retail price

$$
p_{s c}^{c^{*}}<p_{s c}^{c s^{*}}<p_{s c}^{w p^{*}}
$$

Proposition 5. In centralized supply chain model, the retail price is the lowest; the retail price of costsharing contract model comes second; in wholesale price contract model, the retail price is the highest. 
(2) Sales effort $x^{c^{*}}>x^{c s^{*}}>x^{w p^{*}}$

Proposition 6. The centralized supply chain gets the highest sales effort; the cost-sharing contract model comes second; the sales effort of the wholesale price contract model is the lowest.

(3) Demand

$D^{c^{*}}>D^{c s^{*}}>D^{w p^{*}}$

Corollary 1. The demand in centralized supply chain is the highest; the cost-sharing contract model comes second; in wholesale price contract model, the demand is the lowest.

(4) The supply chain profit

$\pi_{s c}^{c^{*}}>\pi_{s c}^{c c^{*}}>\pi_{s c}^{w p^{*}}$

Corollary 2. The centralized supply chain achieves the highest total supply chain profit; the costsharing contract model comes second; in wholesale price contract model, the supply chain profit is the lowest.

\section{Conclusion}

We have analyzed the issue of supply chain coordination between a supplier and a retailer with price and sales effort dependent demand. By means of game theory, we have analyzed two distinct channel structures: centralized supply chain and decentralized supply chain. We have studied price and sales effort decisions of the centralized supply chain, in which the members aim to maximize the total expected profit of the supply chain. Then we consider three different contracts under decentralized model, i.e., wholesale price contract, cost-sharing contract and a two-part tariff contract, in which the supplier offers a contract comprising a wholesale price and a lump-sum fee to the retailer. Finally, we have analyzed the results to compare the equilibrium decisions under different contract scenarios. Our results have shown that both the wholesale price contract and the cost-sharing contract could not coordinate the supply chain. We have found that the centralized supply chain could achieve the lowest retail price, the highest sales effort, the highest demand and the highest total supply chain profit; the cost-sharing contract model comes second; in wholesale price contract model, the retail price was the highest and the sales effort, demand and the total supply chain profit were the lowest. Furthermore, the two-part tariff contract could effectively coordinate the supply chain.

There are several directions for future research. First, we assume a linear demand function and certain demand, the incorporation of non-linear demand function and demand uncertainty would provide even richer results in this framework. Secondly, we can extend this case to the supply chain with two competitive retailers or two competitive supply chains. Finally, this paper assumes that the sales effort of the retailer is common knowledge, extending this model by considering a system with asymmetric information may yield some more interesting results.

\section{References}

Bernstein, F., Chen, F., \& Federgruen, A. (2006). Coordinating supply chains with simple pricing schemes: the role of vendor-managed inventories. Management Science, 52 (10),1483-1492.

Bernstein, F., \& Federgruen, A. (2004). A general equilibrium model for industries with price and service competition. Operations Research, 52 (6),868-886.

Bernstein, F., \& Federgruen, A. (2007). Coordination Mechanisms for Supply Chains Under Price and Service Competition. Manufacturing \& Service Operations Management, 9 (3),242-262.

Boyaci, T., \& Gallego, G. (2004). Supply chain coordination in a market with customer service competition. Production and Operations Management, 13 (1),3-22.

Cachon, G.P., \& Lariviere, M.A. (2005). Supply chain coordination with revenue-sharing contracts: 
strengths and limitations. Management Science, 51 (1),30-44.

Chen, K.-Y., Kaya, M., \& Özer, Ö. (2008). Dual sales channel management with service competition. Manufacturing \& Service Operations Management, 10 (4),654-675.

Dan, B., Xu, G., \& Liu, C. (2012). Pricing policies in a dual-channel supply chain with retail services. International Journal of Production Economics, 139 (1),312-320.

Giannoccaro, I., \& Pontrandolfo, P. (2004). Supply chain coordination by revenue sharing contracts. International Journal of Production Economics, 89 (2),131-139.

Gurnani, H., Erkoc, M., \& Luo, Y. (2007). Impact of product pricing and timing of investment decisions on supply chain co-opetition. European Journal of Operational Research, 180 (1),228248.

He, Y., Zhao, X., Zhao, L., \& He, J. (2009). Coordinating a supply chain with effort and price dependent stochastic demand. Applied Mathematical Modelling, 33 (6),2777-2790.

Hou, J., Zeng, A.Z., \& Zhao, L. (2010). Coordination with a backup supplier through buy-back contract under supply disruption. Transportation Research Part E: Logistics and Transportation Review, 46 (6),881-895.

Iyer, G. (1998). Coordinating channels under price and nonprice competition. Marketing Science, 17 (4),338-355.

Karray, S. (2013). Periodicity of pricing and marketing efforts in a distribution channel. European Journal of Operational Research, 228 (3),635-647.

Krishnan, H., Kapuscinski, R., \& Butz, D.A. (2004). Coordinating contracts for decentralized supply chains with retailer promotional effort. Management Science, 50 (1),48-63.

Linh, C.T., \& Hong, Y. (2009). Channel coordination through a revenue sharing contract in a twoperiod newsboy problem. European Journal of Operational Research, 198 (3),822-829.

Lu, J.C., Tsao, Y.C., \& Charoensiriwath, C. (2011). Competition under manufacturer service and retail price. Economic Modelling, 28 (3),1256-1264.

Ma, P., Wang, H., \& Shang, J. (2013a). Contract design for two-stage supply chain coordination: Integrating manufacturer-quality and retailer-marketing efforts. International Journal of Production Economics

Ma, P., Wang, H., \& Shang, J. (2013b). Supply chain channel strategies with quality and marketing effort-dependent demand. International Journal of Production Economics

Mukhopadhyay, S.K., Su, X., \& Ghose, S. (2009). Motivating retail marketing effort: optimal contract design. Production and Operations Management, 18 (2),197-211.

Perry, M.K., \& Porter, R.H. (1990). Can resale price maintenance and franchise fees correct suboptimal levels of retail service? International Journal of Industrial Organization, 8 (1),115-141.

Sethi, S.P., Yan, H., \& Zhang, H. (2004). Quantity Flexibility Contracts: Optimal Decisions with Information Updates*. Decision Sciences, 35 (4),691-712.

Tang, X., Fang, S., \& Cheng, F. (2012). Strategic interactions in service supply chain with horizontal competition. TOP,1-20.

Taylor, T.A. (2002). Supply chain coordination under channel rebates with sales effort effects. Management Science, 48 (8),992-1007.

Tsay, A.A. (1999). The quantity flexibility contract and supplier-customer incentives. Management Science, 45 (10), 1339-1358.

Tsay, A.A., \& Agrawal, N. (2000). Channel dynamics under price and service competition. Manufacturing \& Service Operations Management, 2 (4),372-391.

Wong, W.-K., Qi, J., \& Leung, S. (2009). Coordinating supply chains with sales rebate contracts and vendor-managed inventory. International Journal of Production Economics, 120 (1),151-161.

Wu, D. (2011). Coordination of competing supply chains with news-vendor and buyback contract. International Journal of Production Economics

Yao, Z., Leung, S.C.H., \& Lai, K. (2008). Manufacturer's revenue-sharing contract and retail competition. European Journal of Operational Research, 186 (2),637-651. 